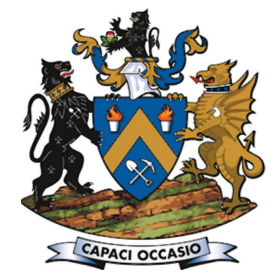

Affiliation:

1 University of the Witwatersrand, South Africa.

Correspondence to:

I.N.M. Nday

Email:

isaacndayone@gmail.com

\section{Dates:}

Received: 6 Feb. 2019

Revised: 5 Apr. 2019

Accepted: 16 Apr. 2019

Published: July 2019

\section{How to cite:}

Nday, I.N.M. and Thomas, $\mathrm{H}$.

Optimization of the cycle time to increase productivity at Ruashi

Mining.

The Southern African Insitute of Mining and Metallurgy

DOI ID:

http://dx.doi.org/10.17159/2411$9717 / 624 / 2019$

ORCID ID:

I.N.M. Nday

https://orchid.org/0000-00031802-3609

\title{
Optimization of the cycle time to increase productivity at Ruashi Mining
}

\author{
I.N.M. Nday ${ }^{*}$ and H. Thomas ${ }^{1}$ \\ *Paper written on project work carried out in partial fulfilment of \\ BSc.Eng (Mining Engineering) degree
}

\section{Synopsis}

The optimization of the cycle time to increase productivity at Ruashi Mining was an on-site project investigation conducted from December 2017 to January 2018. The main objective of the investigation was to determine the actual cycle time components. These comprise the queuing time, loading time, hauling time, and dumping time of ADTs (articulated dump trucks). Data was also collected on two hydraulic shovels to identify where these could be optimized. The actual cycle time obtained was compared to the theoretical cycle time to ascertain the constraints, which affect productivity. By applying Systems Thinking to the cycle time, man-made constraints of the actual cycle time were identified and recommendations to mitigate them suggested to optimize the cycle time. However, rainfall is a natural constraint that adversely affects the actual cycle time, and which cannot be mitigated.

In addition, both the theoretical and actual cycle time were analysed, as well as the theoretical and actual productivity for the year 2017. Based on the findings, conclusions and recommendations were made to optimize the cycle time.

\section{Keywords}

opencast mining, cycle time, optimization, productivity.

\section{Introduction}

The aim of the project was to increase Ruashi Mining's productivity by $39 \%$, from about $7.537 \mathrm{Mt}$ of broken material mined to $12 . .367$ Mt targeted in 2017 .

\section{Background}

Ruashi Mining is a copper (main commodity), cobalt (by-product), and acid producer located in the Democratic Republic of Congo (DRC), $10 \mathrm{~km}$ from the city of Lubumbashi. Figure 1 shows the location of the Ruashi Mining open pit.

Ruashi Mining started production in 1911 and in 2005 the mine was registered as a DRC company owned by Metorex Group Limited. In November 2013, the Chinese company Jinchua Group International Resources Co. Ltd. bought a majority stake in the business. Ruashi Mining currently produces $38000 \mathrm{t}$ of copper and $4400 \mathrm{t}$ of cobalt per annum. The company has contracted NB Mining (a contract mining company) to transport its ore. To optimize the productivity of the mine, considering ore flow delivery at Ruashi Mining, the cycle time is the indicator used in this project. The cycle time components were recorded on site using a stopwatch.

\section{Problem statement}

There are many ways in which the productivity of a mine can be optimized, one way being by decreasing the actual cycle time. At Ruashi Mining there are constraints affecting and extending the cycle as shown in Figure 2. The constraints need to be identified and eliminated or mitigated to optimize the cycle time, which will increase productivity in terms of the tonnage of broken rock transported per annum.

\section{Literature survey}

To structure this project, a Master's project on the optimization of the haulage cycle model for open pit mining using a simulator and a context-based alert system was reviewed.

By utilizing mining software, simulations of an actual system in a process can be generated. Parameters of the simulation can be modified several times with the aim of looking for the ultimate optimization model. In this way it is possible to save costs, resources, and time. 


\section{Optimization of the cycle time to increase productivity at Ruashi Mining}

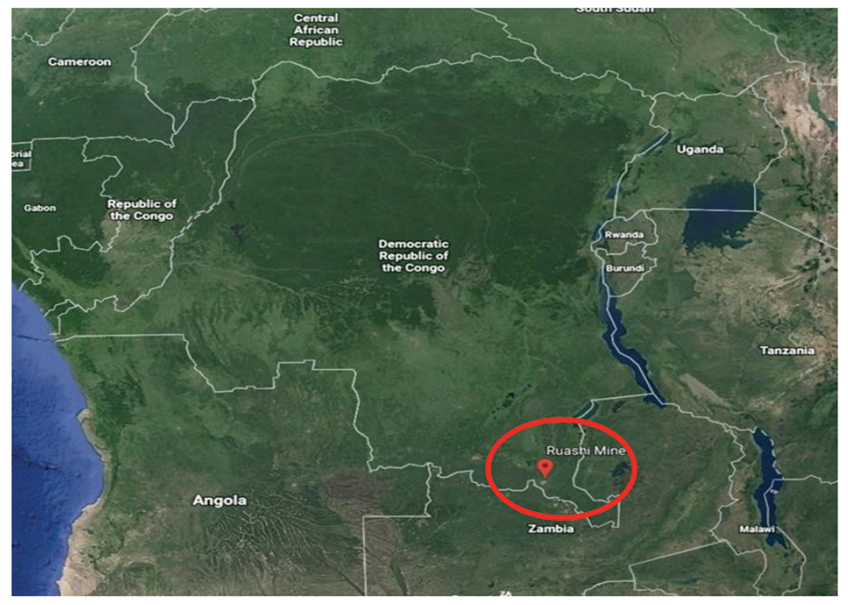

Figure 1-Location of Ruashi Mining in the southern part of the DRC (Google Earth, 2018)

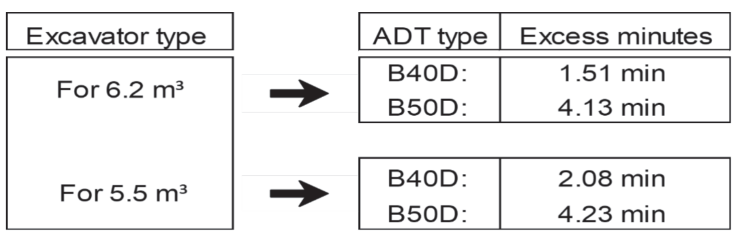

Figure 2-Excess minutes in the cycle time per excavator and ADT type

Furthermore, an As-Is and a To-Be model were developed to represent the haulage route of an open pit mining operation so that the cycle time can be optimized. Values generated with the As-Is model were subsequently adjusted in the To-Be. This model could be used for other mines, taking into account their parameters such as the production, geology, and haulage equipment.

The main goal of the project was to develop a methodology to improve productivity, reduce unproductive time, increase truck and shovel utilization, and reduce the queuing time for shovels and the crusher by applying simulation techniques, without incurring any additional investment.

In addition, the As-Is model allowed for the representation of a mine operating at a particular time, and the To-Be model showed how the operation would look after certain adjustments. (Vasquez Coronado, 2014).

Ercelebi and Bascetin (2009) developed a model based on closed queuing network theory that can be utilized to determine the optimal number of trucks working with each shovel in the system. In addition, using a linear programming model they determined how the ADTs should be dispatched to the shovels. The case study was conducted at the Orhaneli open pit coal mine in Turkey. Ercelebi and Bascetin stated that productivity of the equipment is an important factor in the profitability and that shovel-truck systems are the most common in open pit mining. The aim of developing a model was to maximize productivity and hence increase production, which in turn will result in cost reduction and increased profitability.

At Ruashi Mining ADTs do not arrive at the shovel at consistent times, nor does it take the same amount of time for shovels to load trucks. Therefore, the randomness of arrival times of ADTs at the shovel results in queuing time or the shovel being idle while waiting for ADTs to arrive.

A linear programming model (LPM) assumes no ADTs queuing under ideal conditions with maximum shovel utilization. LPM minimizes the number of ADTs required for the shovel utilization without ADTs queuing and is equivalent to maximizing the overall production rate.

Lane (2018) stated that a fundamental understanding of the mining system is vital to maximizing operational output. Systems Thinking is a management discipline used to comprehend different components constituting a system and to examine how these components link and interact to contribute to the overall system efficiency.

The mining system comprises different activities that interlink and when the optimum performance of each activity is obtained, the targeted throughput can be produced. An underperforminig activity compromises the total throughput. Therefore, it is imperative to thoroughly understand the mining system to identify a constraining activity in that system and optimize it to improve the mining output. It is worth noting that, optimizing a non-constraint activity will not have as great an impact on the overall throughput as optimizing a constraint ( Goldratt, n.d.).

The Theory of Constraints is a methodology for identifying the most important constraint that compromises the mine throughput and then systematically improving that constraint until it is no longer the limiting factor. Sets of tools provided by the Theory of Constraints to maximize the mine throughput are:

1. The five focusing steps (used to identify and eliminate constraints) as shown in Figure 3.

2. The thinking processes (used to analyse and resolve problems).

These are designed with cause-and-effect tools. Firstly, identify the cause of undesirable effects, and secondly eliminate them without creating new ones. Thinking processes answers three questions:

What needs to be optimized?

What should it be optimized to?

- What actions will lead to the optimization?

3. Throughput accounting (a method for measuring performance and guiding management decisions) (Goldratt, n.d.).

Catoca Mining Society (CMS) is an opencast diamond mine which was assessed with the purpose of productivity optimization. The production rates at the mine were neither constant nor did they follow the designed or planned output. As a strategy to overcome the issue, the mine increased the unit 


\section{Optimization of the cycle time to increase productivity at Ruashi Mining}

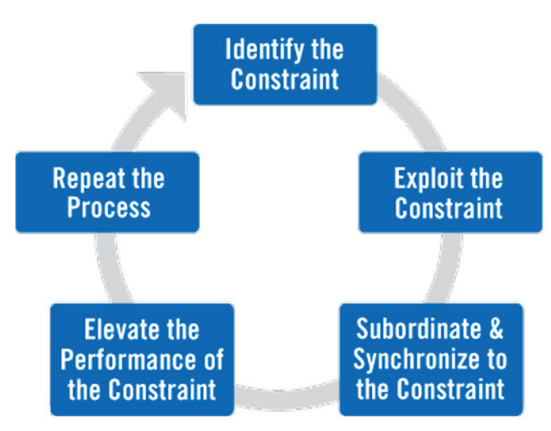

Figure 3-Five focusing steps to identify and eliminate constraints

numbers for both excavators and haulage to operate at maximum efficiency. The operational conditions such as the weather, breakdowns, and maintenance were to be considered because these conditions could disrupt the hauling and loading operation.

Achieving shovel productivity is dependent on having adequate ADT coverage to minimize shovel delays. In addition, the availability of the shovel and ADT system is a crucial parameter to consider, as it dictates the utilization and subsequently the output (productivity) of the system.

The parameters affecting the loading/haulage cycle were identified and simulated accordingly to determine the optimum operation cycle. Furthermore, the results have shown that for a distance of $2.7 \mathrm{~km}$, six ADTs should be used for optimal efficiency (Vemba, 2004).

Mkhatshwa (2009) investigated the Mamatwan opencast manganese mine in South Africa, which was failing to reach its daily production target. This was due to factors such as road conditions, and poor matching of ADTs and shovels. Mkhatshwa further stated that properly designed haul roads result in minimum traffic congestion and thus increase the production efficiency of the ADTs.

Mkhatshwa also stated that by correctly matching the equipment, production can be improved by minimzsing the loading time and obtaining 95\% loading of ADTs. In practice, it is impossible to achieve a $100 \%$ load for the ADTs.

\section{On-site investigation}

The on-site investigation included the time spent at the Ruashi
Mining, under NB Mining. The purpose was to investigate the mining operations, to identify constraints and to collect cycle time data to determine the total actual cycle time for optimization to be realized.

\section{Interpretation of data}

The interpretation of the data (analysis and results) included statistical calculations to find the average loading, hauling, and manoeuvring time (dumping and queuing times). The actual cycle time was then compared to the theoretical cycle time and the excess times were determined for each cycle time component.

\section{Systems Thinking applied to optimize the cycle time}

\section{Approach to optimize the cycle time}

By definition, Systems Thinking is a management discipline used to comprehend different components constituting a system and examine how these components link and interact to contribute to the overall system efficiency (Lane, 2018). Figure 4 shows the cycle time system with individual activities.

The cycle time system consists of different activities; namely, the loading time, travelling time with ADTs loaded, queuing time at the run-of-mine (ROM) pad, dumping time at the ROM pad stockpiles, hauling time with ADTs unloaded, and queuing time at the loading point. For an optimal cycle time to be achieved, the abovementioned activities must be performing efficiently. Therefore, to optimize the cycle time, the constraining activity must be identified and mitigated.

\section{Constraint identified in the cycle time system}

By considering the cycle time as a system, and knowing that every system has a constraint, it is imperative to identify the constraint(s) in the cycle time system to be able to optimize that system.

From the on-site investigation and data analysis, the following constraints were identified:

$>$ Work ethics of the operators (operators stopping the ADTs to discuss trivial matters, e.g. sport, for a short period of time)

$>$ Mine road conditions

> Condition of equipment

$>$ Long queuing time of the ADTs at the shovel.

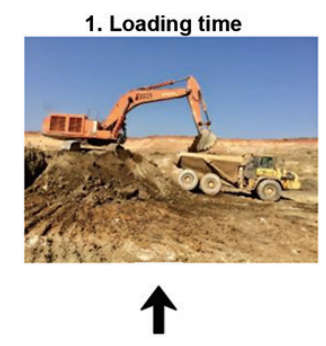

6. Queuing time before loading

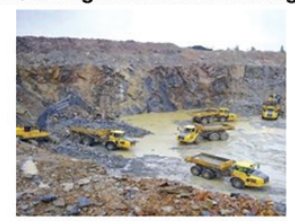

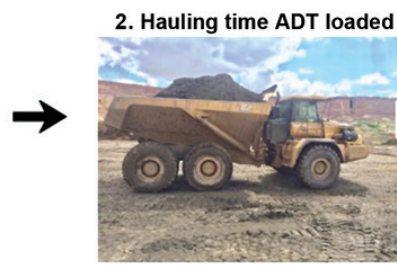

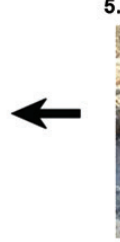

5. Hauling time ADT unloaded

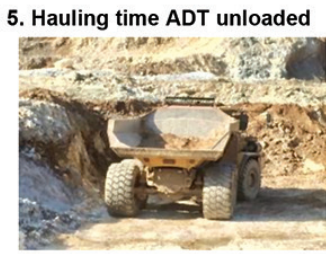

3. Queuing time at the ROM pad
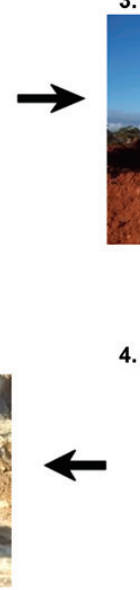

4. Dumping time at the ROM pad

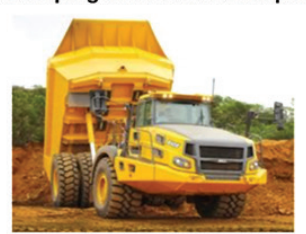

Figure 4-The cycle time system with individual activities 


\section{Optimization of the cycle time to increase productivity at Ruashi Mining}

To optimize the cycle time, these activities must be mitigated, starting with the most important and proceeding to the least important. Furthermore, to optimize the present cycle time, there is a need to be aware of the theoretical cycle time, which would be compared to the actual cycle time.

\section{On-site data analysis}

The data collected on-site was analysed and used for the calculation of the actual cycle time to be optimized. The analysis included:

$>$ Queuing time

- Hauling time

- Dumping time

$>$ Production data.

The production data collected revealed a failure to reach the daily production target as well as the monthly target of excavated material (ore and waste) to be delivered to different destinations. To add value to Ruashi Mining, there must be consistent ore delivery to the ROM pad.

Figure 5 shows Ruashi Mining's monthly production for the year 2017. The targeted production was met or surpassed in only 4 out of the 12 months. As a result, the 2017 Ruashi Mining annual production target was not achieved.

\section{Influence of rainfall}

The southern part of the DRC has a tropical climate, with the rains from mid-November to the beginning of April. Consequently, open pit mining operations are affected negatively during this period.

- ADT hauling speed is decreased

- Mud accumulayes on the mine roads and in the open pit

> During heavy rain, the operations stop due to safety concerns and access issues. The Ruashi open pit contains talc, which becomes slippery when wet. Consequently, it is dangerous to operate mining equipment under such conditions.

However, Ruashi Mining continues to operate during this period because of ore stockpiled at the ROM pad. Figure 6 shows the monthly production for the year 2017-2018, highlighting the effect of rainfall on production.

The monthly production achieved (orange trendline) is below the targeted production (blue trendline) from mid-November 2017 to the beginning of April 2018.

\section{Theoretical cycle time calculation}

The average cycle time is obtained as follows:

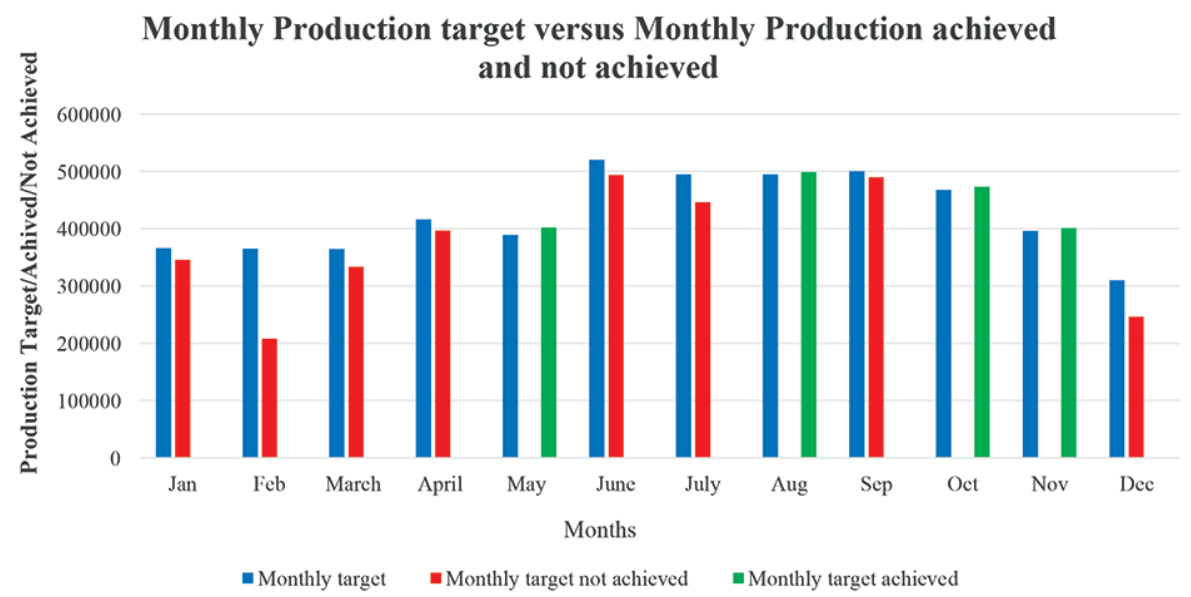

Figure 5-Monthly production versus target at Ruashi Mining

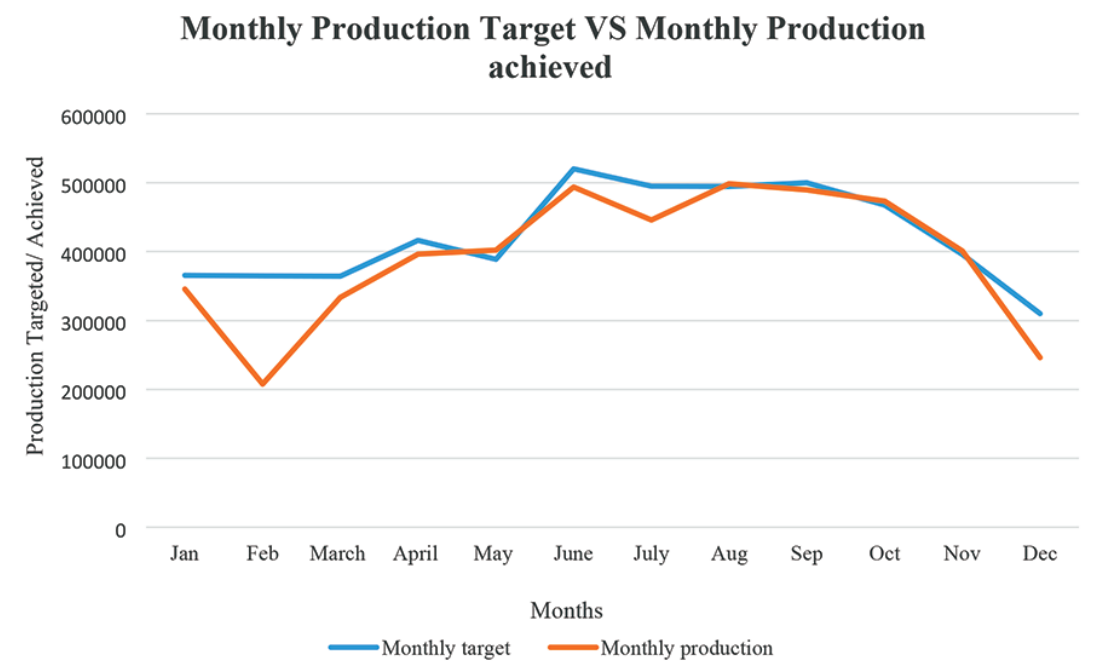

Figure 6-Effect of the the rainfall season on monthly production at Ruashi Mining 


\section{Optimization of the cycle time to increase productivity at Ruashi Mining}

Cycle time $=$ Loading time + hauling time $($ ADT loaded $)+$ Dumping time (raise and lower time) +

hauling time (ADT unloading) + Queueing time

\section{Theoretical queuing time results}

When the cycle time is ideal, there are no constraints compromising an operation. By reviewing the paper by Ercelebi and Bascetin (2009), it could be concluded that in an ideal cycle time there is no queuing of the ADTs at the shovel.

\section{Theoretical loading time results}

The loading time is the sum of the times (in minutes and seconds) for the number of passes. For this project, the loading times were recorded for the two Hitachi shovels, namely the Hitachi EX 1200-6 and Hitachi EX 870 LCR-3.

Struck capacity of B40D $\quad 18.5 \mathrm{~m}^{3}$

Struck capacity of B50D $\quad 22 \mathrm{~m}^{3}$

EX 870 LCR-3 capacity $\quad 5.5 \mathrm{~m}^{3}$

EX 1200-6 capacity $\quad 6.2 \mathrm{~m}^{3}$

\section{Equation 2. Loading time}

No. of passes $=$ Loading time $(\min ) \div$

Shovel cycle time (min)

$>$ EX 1200-6 = 28.3 seconds $=0.4717$ minutes

> EX 870 LCR $-3=29$ seconds $=0.4833$ minutes.

\section{Theoretical hauling time results}

$$
\text { Hauling time }=\frac{\text { Set distance }}{\text { Speed of haulers }}
$$

- ADTs are required to travel on a flat surface at $40 \mathrm{~km} / \mathrm{h}$

$>$ ADTs are required to travel up the ramp of $10^{\circ}$ (grade $=$ $\left.10^{\circ} ; \tan \left(10^{\circ}\right) \times 100 \%=17.63 \%\right)$ at a speed of $12 \mathrm{~km} / \mathrm{h}$, and down the ramp at a speed of $20 \mathrm{~km} / \mathrm{h}$

> Assume the rolling resistance (based on the road conditions observed from the on-site investigation) to be $4 \%$
> Total resistance force $=$ Grade + Rolling resistance $=$ $21.63 \%$ (approx. 22\%).

Figure 7 depicts the rim pull chart used to determine the speed of the BELL B40D ADTs. The overall B40D weight was $66851 \mathrm{~kg}$, which is used on the left-hand side graph. An arrow intercepts the $22 \%$ total resistance force and another arrow intercepts the gear in red on the right-hand side graph. A speed of $7 \mathrm{~km} / \mathrm{h}$ is determined from the graph, so that the total hauling time (going and returning) could be determined:

$$
\begin{aligned}
\text { Total hauling time } & =\frac{2.93 \mathrm{~km}}{7 \mathrm{~km} / \mathrm{h}} \\
& =0.4185 \mathrm{~h}(25.11 \text { mintes })
\end{aligned}
$$

The hauling time that the B40D should take to travel from the open pit to the ROM pad and return to the pit is 25.11 minutes. Figure 8 depicts the rim pull chart for the B50D; the grade and the rolling resistance remain constant as for the B40D.

The B50D speed was determined to be $6.5 \mathrm{~km} / \mathrm{h}$ from the B50D rim pull chart, as seen in Figure 8. The overall B50D weight was $79920 \mathrm{~kg}$. The blue arrow is used to illustrate how the speed was determined.

$$
\begin{aligned}
\text { Total hauling time } & =\frac{2.93 \mathrm{~km}}{6.5 \mathrm{~km} / \mathrm{h}} \\
& =0.4508 \mathrm{~h}(27.05 \text { minutes })
\end{aligned}
$$

The hauling time that the B50D should take to travel from the open pit to the ROM pad and return to the open-pit is 27.05 minutes.

\section{Theoretical dumping time results}

The dumping time at the ROM pad includes the raising and lowering of the bucket.

$>$ Dumping time B40D: $13.0+7.6=20.6$ seconds $=$ 0.3433 minutes

$>$ Dumping time B50D: $11.2+9.9=21.1$ seconds $=$ 0.3517 minutes.
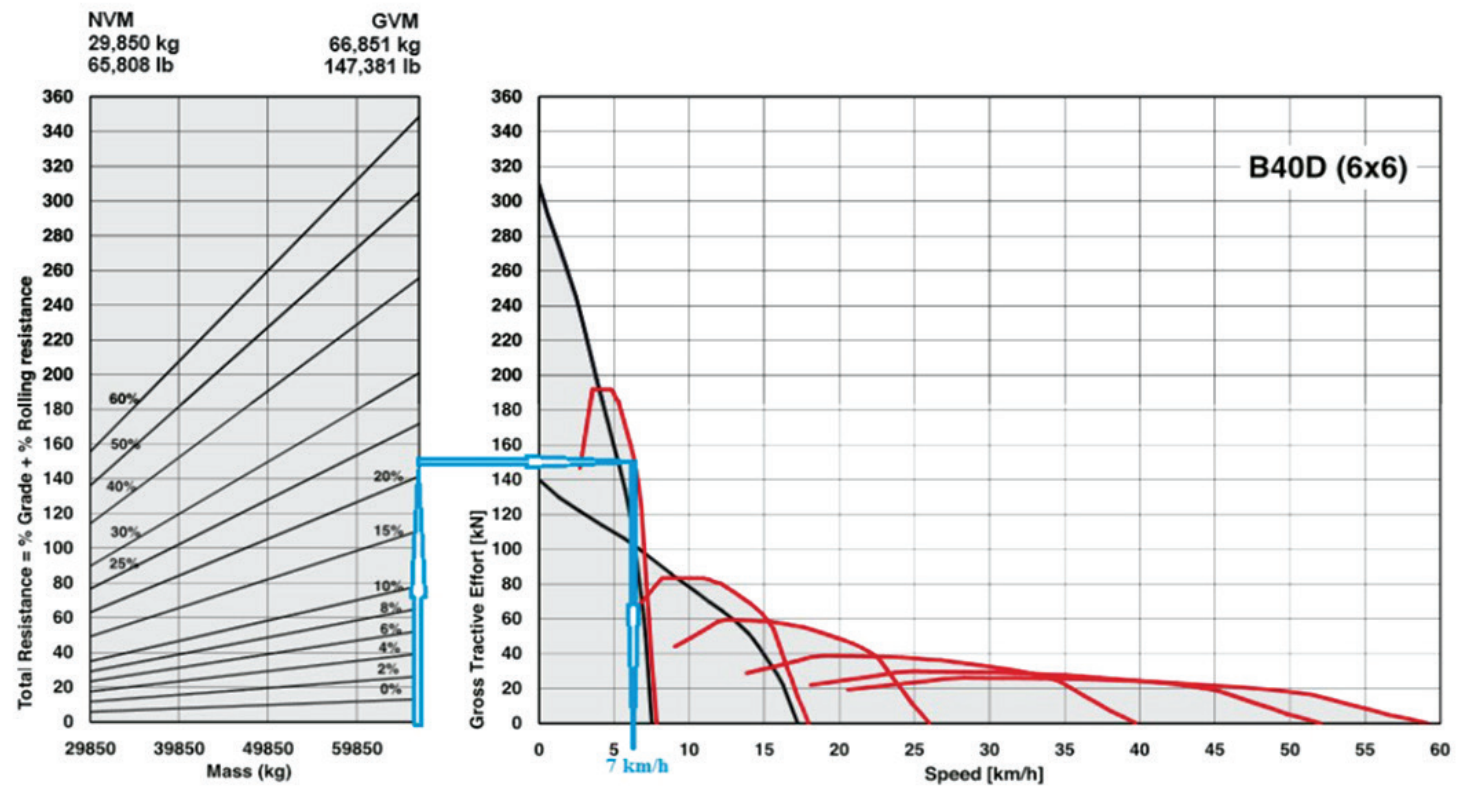

Figure 7-Rim pull chart for the B40D 


\section{Optimization of the cycle time to increase productivity at Ruashi Mining}

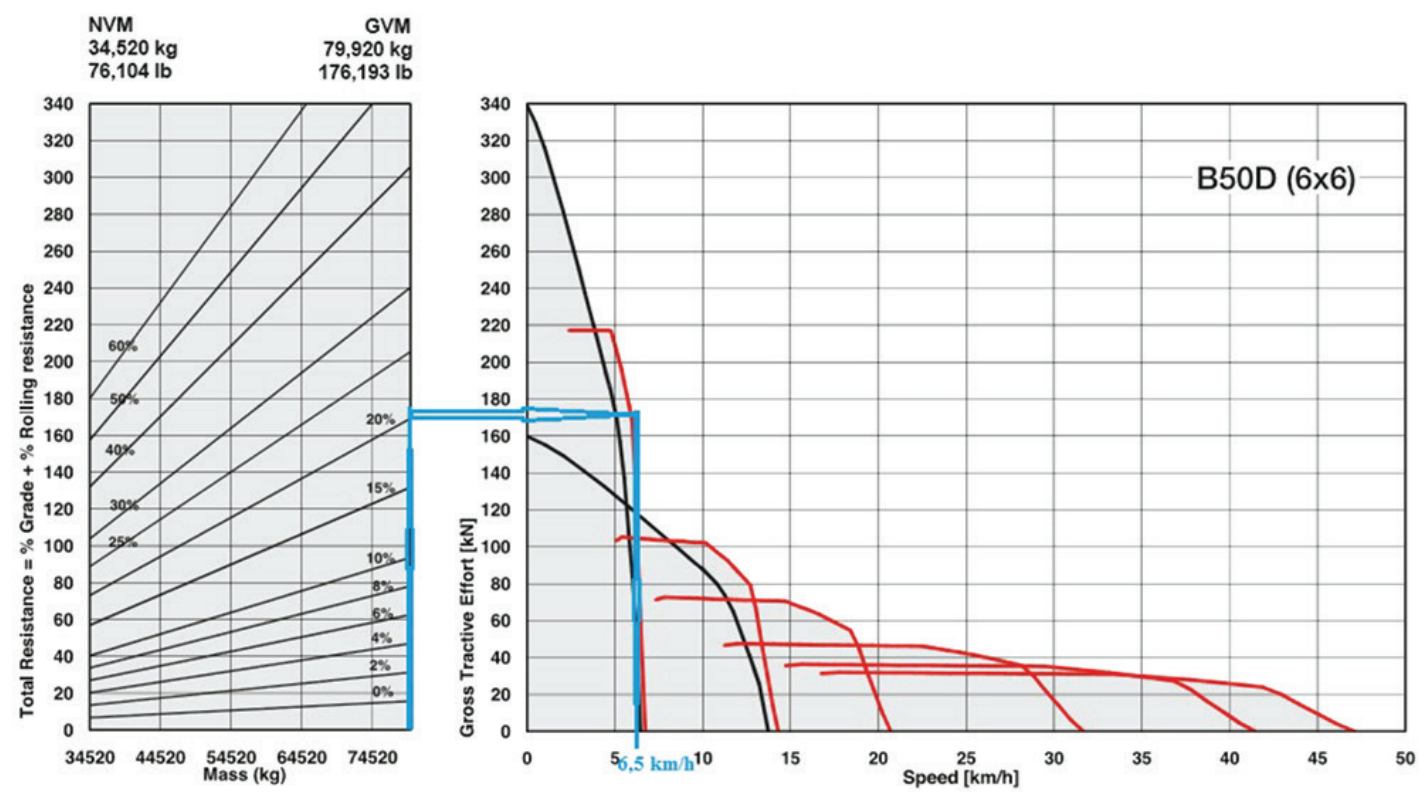

Figure 8-Rim pull chart for the B50D

Table I

Theoretical cycle time results

\begin{tabular}{|c|c|c|c|c|c|}
\hline & \multicolumn{2}{|c|}{ Average time } & & \multicolumn{2}{|c|}{ Average time } \\
\hline & $40 t$ & $50 \mathrm{t}$ & & $40 \mathrm{t}$ & $50 \mathrm{t}$ \\
\hline $\begin{array}{l}\text { Queuing time (min) } \\
\text { Loading time (min) EX } 870 \text { LCR-3 } \\
\text { Hauling time (min) } \\
\text { Dumping time (min) } \\
\text { Average theoretical cycle time (min) }\end{array}$ & $\begin{array}{c}0 \\
0.4833 \\
25.11 \\
0.3433 \\
25.937\end{array}$ & $\begin{array}{c}0 \\
0.4833 \\
27.05 \\
0.3517 \\
27.885\end{array}$ & $\begin{array}{l}\text { Queuing time (min) } \\
\text { Loading time (min) EX } 1200 \\
\text { Hauling time (min) } \\
\text { Dumping time (min) } \\
\text { Average theoretical cycle time (min) }\end{array}$ & $\begin{array}{c}0 \\
0.4717 \\
25.11 \\
0.3433 \\
25.925\end{array}$ & $\begin{array}{c}0 \\
0.4717 \\
27.05 \\
0.3517 \\
27.873\end{array}$ \\
\hline
\end{tabular}

Table II

Actual cycle times for different shovels and payloads

\begin{tabular}{|c|c|c|c|c|c|}
\hline & \multicolumn{2}{|c|}{ Average time } & & \multicolumn{2}{|c|}{ Average time } \\
\hline & $40 t$ & $50 t$ & & $40 t$ & $50 t$ \\
\hline $\begin{array}{l}\text { Queuing time (min) } \\
\text { Loading time (min) EX } 870 \text { LCR-3 } \\
\text { Hauling time (min) } \\
\text { Dumping time (min) } \\
\text { Average theoretical cycle time (min) }\end{array}$ & $\begin{array}{l}03: 36.0 \\
02: 01.0 \\
21: 59.4 \\
00: 25.2 \\
28: 01.6\end{array}$ & $\begin{array}{l}03: 36.0 \\
02: 12.2 \\
25: 59.5 \\
00: 24.3 \\
32: 11.7\end{array}$ & $\begin{array}{l}\text { Queuing time (min) } \\
\text { Loading time (min) EX } 1200 \\
\text { Hauling time (min) } \\
\text { Dumping time (min) } \\
\text { Average theoretical cycle time (min) }\end{array}$ & $\begin{array}{l}03: 36.0 \\
01: 43.6 \\
21: 59.4 \\
00: 25.2 \\
27: 44.2\end{array}$ & $\begin{array}{l}03: 36.0 \\
02: 00.5 \\
25: 59.5 \\
00: 24.3 \\
32: 00.0\end{array}$ \\
\hline
\end{tabular}

\section{Theoretical cycle time results}

The theoretical cycle time is the ideal cycle time. Table I shows the theoretical cycle time results after calculating different components making up the total theoretical cycle time.

Different shovels give different loading times, depending on their capacities when loading ADTs of different payloads. This will result in different theoretical cycle times, as can be seen in Table I.

\section{Actual cycle time calculations}

The actual cycle time was calculated from the data collected on site using a stopwatch. A summary of the actual cycle time components is shown in Table II.
It is worth noting that the loading time data was collected for two different shovels, and that affects the actual cycle times.

\section{Theoretical cycle time versus actual cycle time analysis}

The main differences between the theoretical and actual cycle times are in the input assumptions.

The purpose of calculating the theoretical (ideal) cycle time was to determine the benchmark to optimize the actual cycle time. In addition, the theoretical cycle time was calculated with the data obtained from the manufacturer's specification booklets, whereas the actual cycle time was calculated with data collected on site. Figure 9 shows the chart comparing the actual and theoretical cycle time of a Hitachi EX 1200-6 shovel. 


\section{Optimization of the cycle time to increase productivity at Ruashi Mining}

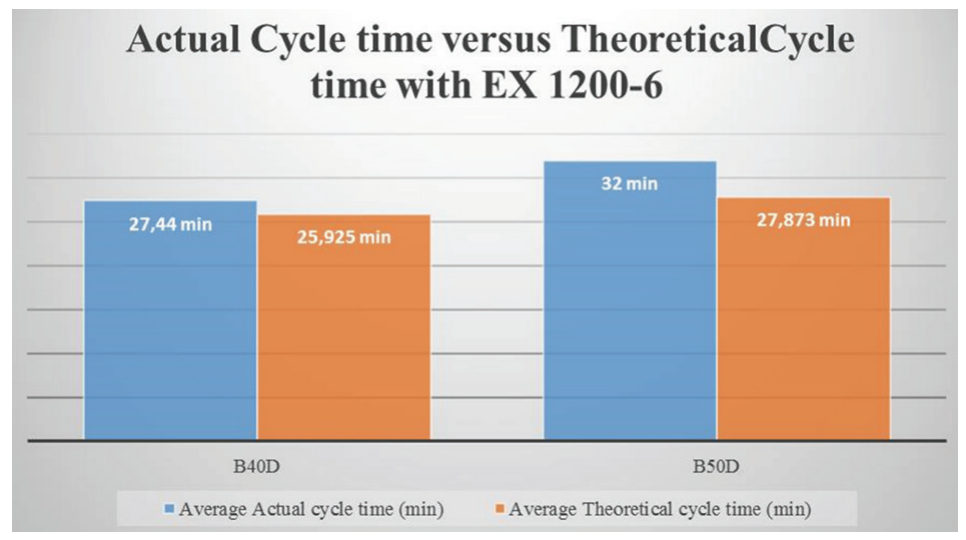

Figure 9-Actual versus theoretical cycle time for the EX 1200-6

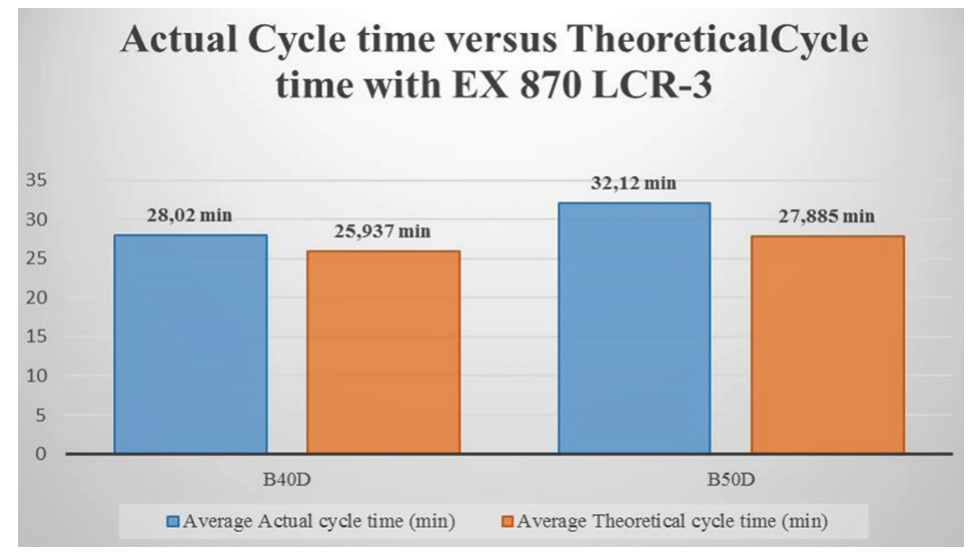

Figure 10-Actual versus theoretical cycle time for the EX 870 LCR-3

As expected, the actual cycle time is longer than the theoretical cycle time. For the B40D, the difference in cycle time is 1.52 minutes and for the B50D the difference is 4.13 minutes. By mitigating the constraints identified, the cycle time will be optimized, and the actual cycle time will be reduced to a time equal to or better than the theoretical cycle time. Figure 10 shows the actual versus theoretical cycle time for a Hitachi shovel EX 870 LCR-3.

From Figure 10, with a Hitachi 870 LCR-3, the difference in the cycle time of the B40D is 2.08 minutes and that for the B50D is 4.24 minutes. There is also a need to optimize this cycle time as the gap (largely caused by the queuing time) between the theoretical and the actual cycle time is significant.

\section{Production calculation}

\section{Production data interpretation}

The production data to be analysed was collected on the mine. Shift data:

> Two shifts per day

- Eleven hours per shift (ideal scenario)

> Nine effective working hours per shift, i.e. 18 effective working hours per day.

\section{Planned versus actual production per annum}

Equations [5] to [7] are used to calculate the annual production (planned and achieved) in 2017. By knowing the planned tons production per ADT and the number of trucks operating on the mine, the calculations could be done as follows:

$$
\begin{aligned}
& \text { Cycles per hour }=\text { Cycle time }(\min ) \div 60 \\
& \text { Tons per annum }(t)=\text { Tons per day } x \\
& \text { Number of days per annum } \\
& \text { Tons per annum }(t)=\text { Tons per day } x \\
& \text { Number of days per annum }
\end{aligned}
$$

ADTs and shovels have surpassed the required working hours, which has become a constraint as identified during the onsite investigation. Consequently, unpredictable breakdowns occur, which affect the machine availability and utilization as shown in Table III.

As a result, there was a $39.06 \%$ shortfall in production in 2017-2018, with 4830403.91 t of unmoved material being the outcome of the longer cycle time due to the constraints.

\section{Conclusions}

There are two types of constraints identified in the production mining cycle. There are man-made constraints identified through Systems Thinking analysis (i.e. the mine roads and condition of equipment, lack of work ethic from the operators, bucket fill 


\section{Optimization of the cycle time to increase productivity at Ruashi Mining}

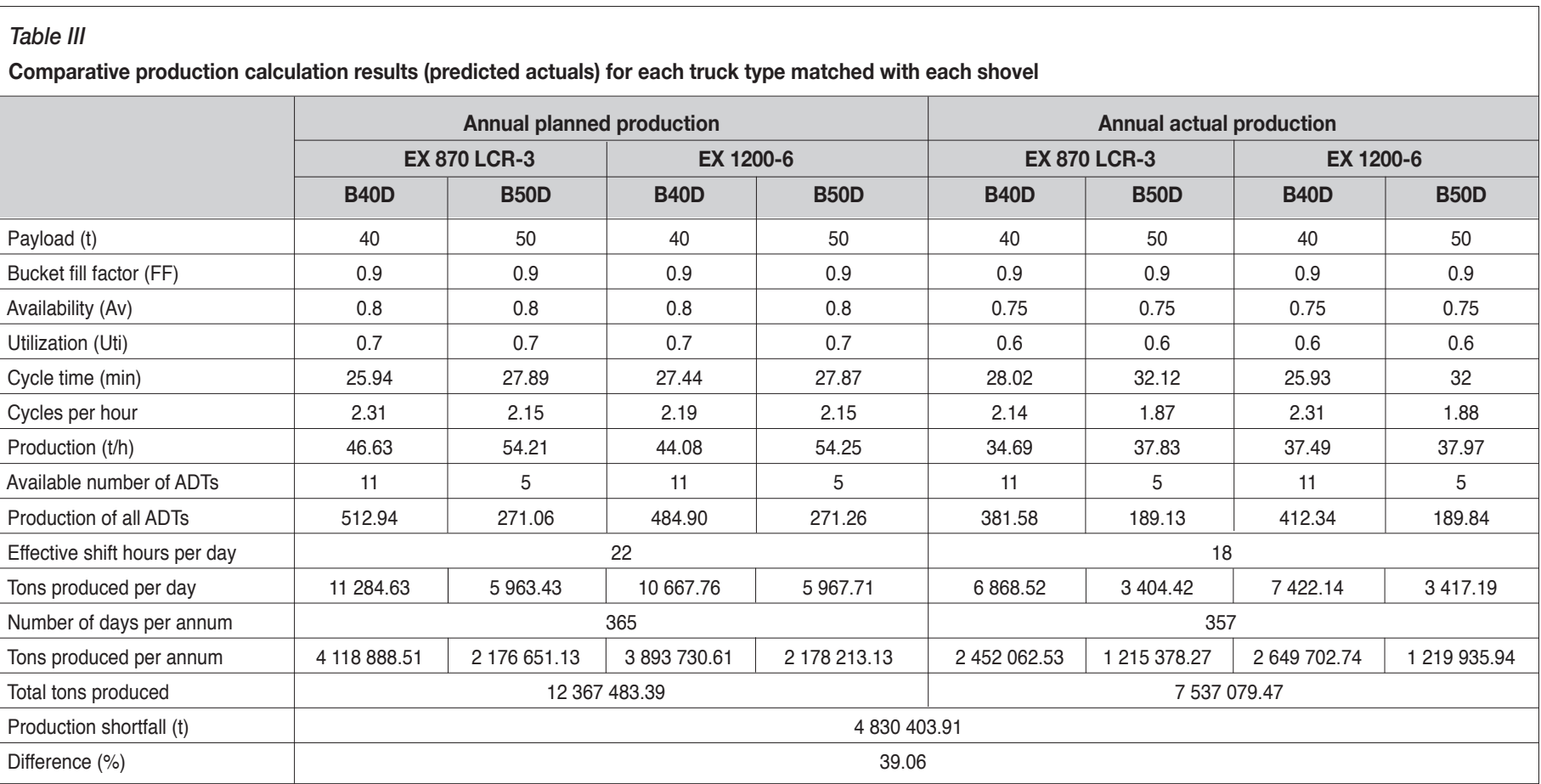

factor of the shovel, and the queuing of ADTs at the shovel). There is also a naturally occurring constraint, which is the rainfall from mid-November to the beginning of April. This constraint cannot be mitigated.

From the analysis of the results, the actual cycle time of a B40D ADT can be reduced by $8 \%$ (from 28.02 minutes to 25.94 minutes) when used with the Hitachi 870 LCR-3 shovel. Moreover, the actual cycle time for the B50D ADT can be reduced by $13.2 \%$ (from 32.12 minutes to 27.89 minutes) using the Hitachi 870 LCR-3. When excavating with the Hitachi 1200-6 shovel, the actual cycle time can be reduced by $5.5 \%$ (from 27.44 minutes to 25.94 minutes) for the B40D ADT and by $12.9 \%$ (from 32 minutes to 27.87 minutes) for the B50D ADT.

Finally, a reduction in cycle time increases production as it can achieve a higher tonnage per hour and per shift. The production can be increased with the same resources and fixed costs by optimizing the productivity through Systems Thinking. Eventually, the increase in the financial performance of the mine may extend the life of mine (LOM) as it will allow access to previously uneconomical reserves. Ultimately, the positive impact on the country will be tangible through royalties, taxes, and the economy.

\section{Recommendations}

> Scheduled mine roads and equipment maintenance. Mine roads must be regularly maintained, especially during the rainy season, to allow smooth running of the mine operations

> Empowering the workers would be an effective way to overcome their poor work ethic, by demonstrating the impact their work has on the overall mine operation and output. Proving to workers how losing minutes discussing trivial matters adversely affects the daily, monthly, and yearly cycle time, therefore, the productivity (Lane, 2018)

> It was observed from the on-site investigation and proven by data analysis that the inconsistency in the loading time data must have been caused by the shovel bucket filling factor. NB Mining must reinforce its operator-training programme so that the operators have the competency to operate the shovels at full efficiency

> The following formula can be used to calculate the number of trucks required per shovel. This will reduce the queuing time of the ADTs at the shovel. For the purpose of this calculation, the actual hauling and loading cycle times are used because they are based on the data collected on-site.

$$
\begin{aligned}
\text { No of trucks required per shovel } & =1+\frac{\text { Hauling cycles time (minutes) }}{\text { Loading cycle time (minutes) }} \\
& =1+\frac{21.59}{2.01}=10.74 \approx 11_{\mathrm{ADTS}(\mathrm{EX} 870 \mathrm{LCR}-3 \text { loading B40D) }} \\
& =1+\frac{25.60}{2.12}=12.07 \approx 13_{\mathrm{ADTS}(\mathrm{EX} 870 \text { LCR-3 loading B50D) }} \\
& =1+\frac{2.59}{1.44}=14.99 \approx 15_{\mathrm{ADTS}(\mathrm{EX} 1200-6 \text { loading B40D) }} \\
& =1+\frac{25.60}{2.00}=12.80 \approx 13_{\mathrm{ADTS}(\mathrm{EX} 1200-6 \text { loading B50D) }}
\end{aligned}
$$

Future studies can be conducted on:

> Application of Systems Thinking in mining to optimize a mine's throughput

> Adding value to a mine by saving costs on diesel when implementing 'stop-start systems' on ADTs.

\section{References}

GoldRatT, E. Not dated. Theory of Constraints - Lean Manufacturing. https://www. leanproduction.com/theory-of-constraints.html [accessed 29 March 2018].

VASQUEZ CoRonAdo, P.P. 2014. Optimization of the haulage cycle model for open pit mining using a discrete-event simulator and a context-based alert system. The University of Arizona. http://hdl.handle.net/10150/321594

Ercelebi, S. And Bascetin, A. 2009. Optimization of shovel-truck system for surface mining. Journal of the Southern African Institute of Mining and Metallurgy, vol. 109. pp. 434-437.

LANE, G. 2018. Systems Thinking for mining. Industrial and Research Seminar II. University of the Witwatersrand, Johannesburg.

МкнатSнWА, S. 2009. Optimization of the loading and hauling fleet at Mamatwan open pit mine. Journal of the Southern African Institute of Mining and Metallurgy, vol. 109. pp. 225-226.

VeMBA, M. 2004. Loading and transport system at SMC - Optimization. Journal of the South African Institute of Mining and Metallurgy, vol. 104. pp. 141-146. 